\title{
Gast-Editorial
}

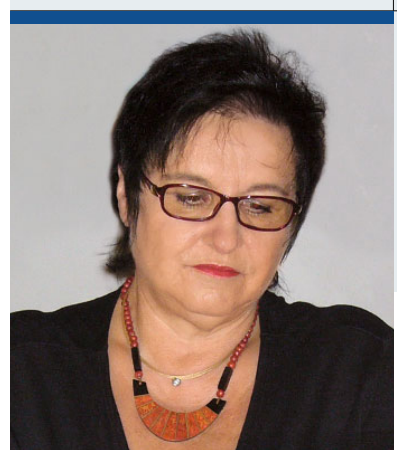

"Wer stoppt den Wagen, der in Richtung
Gesundheitsindustrie rollt?"

Renate Hartwig,

Publizistin und Vorsitzende Bürgerschulterschluss e.V.

\section{Hinter verdunkelten Fenstern}

B etrachten wir die Reise der Gesundheitspolitik, sehen wir auf der Überholspur schnell fahrende Limousinen mit verdunkelten Fenstern. Im Navigationssystem der Rhön Kliniken AG Limousine ist als Ziel „Übernahme der ambulanten Versorgung“ angegeben. Für die Insassen, den Rhön-Vorstandschef Pföhler und den Vorstandsvorsitzenden der Kassenärztlichen Bundesvereinigung (KBV) Köhler steht fest: Der am 6. Juni 2008 vorgestellte Kooperationsvertrag zwischen der KBV und der RHÖN Klinikum AG ist eine strategische Kooperation. Es wurde 2008 von neuen Perspektiven gesprochen, von Grenzen die überwunden werden müssen und von einem Gesundheitssystem, das flexible Strukturen und Sprunginnovationen benötigt. Fast schon peinlich, wie jemand wie KBV-Vorstand Köhler auf Nachfrage dieses Zusammenspiel als weitsichtige Aktion verkauft.

Jeder könnte lachen, wenn es nicht zum Weinen wäre. Meiner Ansicht nach geht es beiden, Pföhler und Köhler, um gemeinsame Nenner, und die heißen: Besitzstandwahrung, Macht und Geld. Köhler, der Kraft seines Amtes die durch Zwangsmitgliedschaft unterstellten Ärzte vertreten sollte, geht auf Kurs mit den Zielen von Rhön! Köhler, demonstriert in der Öffentlichkeit Umarmungen mit Ärzten und spricht von der Sorge um uns Patienten! Bei mir wecken die Köhler-Aussagen immer mehr die Assoziation des Judaskusses.

Wolfgang Pföhler spricht wenigstens aus, was Rhön plant und durchsetzen will. Er sieht die Rhön AG als Sieger im Umbau des Gesundheitswesens! Wolfgang Pföhler auf der Analystenkonferenz: „(..) Ich nenne nur das Konzept der an unseren Konzernkliniken angegliederten medizinischen Versorgungszentren. Unser umfangreich gegliedertes Produktportfolio und die Bereitschaft der Kassen, einen flächendeckenden Service anzubieten. Sie erkennen deutlich, dass die Reformüberlegungen in der Gesundheitsreform uns langfristig in die Hände arbeiten und uns nicht vom Ergebnis Wachstum abbringen werden (...) “

Hier steht das Ziel der Investoren, der Aktionäre, die bedient werden müssen. Von denen ist nichts anderes zu erwarten. Eine AG ist kein Ableger der Mutter-Theresa-Institution. Nur, was sagen die bei Rhön sitzenden Aufsichtsratsmitglieder? Schweigen im Walde! Die sitzen demnach mit in der Limousine und freuen sich über die variablen Aufwandsentschädigungen ihrer Position.

Bis heute habe ich nicht vernommen, dass der SPDBundestagsabgeordnete Prof. Lauterbach, ebenso Aufsichtsrat bei Rhön, sich bei all seinen öffentlichen Auftritten je über die Ziele von Rhön und deren Verhalten gegenüber Beschäftigten, über die inzwischen öffentlich diskutierte Behandlung von Patienten aufgrund der fehlenden Pflegekräfte und den Umgang mit kritischen Ärzten geäußert hat.

Als Wahlvolk, als Leistungserbringer Arzt, als Bürger, Patient und Beitragszahler sollten wir wissen, es nie vergessen und schon gar nicht verdrängen: Es sind die Rahmenbedingungen der Politik, die inländische und ausländische Investoren der Kapitalgesellschaften in der Sicherheit einer großen Rendite wiegen. Es sind unsere Volksvertreter, die Gesetze erlassen und sich weder vor noch im Wahlkampf über die rasante Fahrt der Gesundheitsindustrialisierung äußern. Die Limousinen auf der Überholspur mit dem Ziel, Ausbeutung durch Umbau unseres Gesundheitswesens, können nur durch Bürgerengagement gestoppt werden. Zeigen wir - Arzt und Patient im Schulterschluss - den Rasern auf der Überholspur das Stoppschild. Sagen wir gemeinsam NEIN zum Verkauf von Mensch und Medizin und der gezielten Existenzvernichtung von niedergelassenen Ärzten.

Ihre

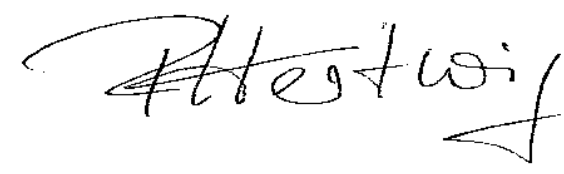

